\title{
Is There Correlation of Facet Joint Pain in Lumbar and Cervical Spine? An Evaluation of Prevalence in Combined Chronic Low Back and Neck Pain
}

\author{
Laxmaiah Manchikanti, MD*, Vijay Singh, MD**, Vidyasagar Pampati, MSc", Kim S. Damron, RN"\#, \\ Carla D. Beyer, RN"\# and Renee C. Barnhill, RN"\#
}

Among the chronic pain problems, pain emanating from cervical and lumbar regions, independently or in combination, constitutes a significant and frequently encountered problem in interventional pain management practices.

This study was designed to test the assumption that patients presenting with chronic low back pain of lumbar facet joint origin may also present with chronic neck pain of facet joint origin. Considering that many studies show the prevalence of facet joint involvement in chronic low back pain as ranging from $15 \%$ to $45 \%$ compared to prevalence of involvement of cervical facets in chronic neck pain, ranging from $54 \%$ to $60 \%$, we sought to evaluate the correlation between lumbar facet joint to cervical facet joint pain.

One hundred twenty consecutive patients with chronic neck

The zygapophysial or facet joints are paired diarthrodial articulations between posterior elements of the adjacent vertebrae (1-3). These joints are formed by the articulation of the inferior articular processes of one vertebra with the superior articular processes of the next vertebrae. It has been assumed that degeneration of the disc and facet joints would lead to low back pain and neck pain. These assumptions were based on the pathogenesis of

From Pain Management Center of Paducah, Paducah, Kentucky and Pain Diagnostics Associates, Niagara, Wisconsin. *Dr. Manchikanti is the medical director at Pain Management Center of Paducah, **Dr. Singh is the medical director at the Pain Diagnostics Associates, ${ }^{\#} \mathrm{Mr}$. Pampati is the statistician and ${ }^{\# M s}$. Damron, Ms. Beyer and Ms. Barnhill are clinical coordinators at Pain Management Center of Paducah. Address correspondence: Laxmaiah Manchikanti, MD, 2831 Lone Oak Road, Paducah, KY 42001. E-mail: drm@apex.net

Funding: No financial support was obtained for this study. and low back pain were evaluated utilizing controlled diagnostic blocks with lidocaine and bupivacaine. The results showed prevalence of cervical facet joint pain in $67 \%$ of the patients with a false-positive rate of $63 \%$ with a single block, whereas the prevalence of lumbar facet joint pain was seen in $40 \%$ of the patients with a $30 \%$ falsepositive rate with a single block in patients presenting with chronic low back and neck pain. There was also significant correlation noted with $94 \%$ of the patients with confirmed lumbar facet joint pain also presenting with cervical facet joint pain.

Keywords: Chronic low back pain, chronic neck pain, lumbar facet joints, cervical facet joints, zygapophysial joints, controlled diagnostic blocks, false-positive rate, prevalence

degenerative cascade in the context of three joint complex that involves the articulation between two vertebrae consisting of the intervertebral disc and adjacent facet joints, as changes within each member of this joint complex will result in changes in others in lumbar and cervical spine (4-9). The prevalence of disc degeneration, spondylosis and facet joint osteoarthritis increase with increasing age (10). Sambrook et al (11) showed simultaneous disc degeneration in cervical and lumbar spine. Similarly, spondylosis is also common in cervical and lumbar spine. Spondylosis is often used to describe vertebral osteophytosis secondary to degenerative disc disease or osteophytosis of the facet joints. But, spondylosis only accurately describes vertebral osteophytosis secondary to degenerative disc disease. Osteophytes occurring at the facet joints are different from osteophytes occurring on the vertebral margins adjacent to the disc. However, radiographic changes of osteoarthritis have been shown to be equally common in patients with and without low back pain and degenerative joints seen on computed tomography $(\mathrm{CT})$ are not always painful, even though some studies report severely degenerated joints as being more likely to be symptomatic. 
Kuslich et al (12) identified facet joints, ligaments, fascia, muscles, intervertebral discs and nerve root dura as tissues capable of transmitting pain in the low back. However 80 years earlier, the concept that facet joints are involved in the etiology of low back pain was described by Goldthwait in 1911 (13). Since then, multiple investigators have implicated zygapophysial joints as cause of low back and neck pain (14). Zygapophysial or facet joints have been implicated as the source of chronic pain in $15 \%$ to $45 \%$ of patients with chronic low back pain (15-21) and 54\% to $60 \%$ of patients with chronic neck pain $(22-24)$. The mechanism of chronic neck pain and low back pain, specifically secondary to facet joints, continues to be controversial. Kirkaldy-Willis et al (4) described the pathogenesis of degenerative changes in the aging spine, whereas Handel et al (9) described a structural degenerative cascade for the cervical spine. In this model, degenerative cascade is viewed in a context of three-joint complex, with involvement of changes in the disc structure and composition paralleling changes in the articular cartilage and ligaments of joints. Thus, it is reasonable to assume that in a patient suffering with neck and low back pain, the causative structures of that pain may be the same in both regions, either discs or facet joints. The potential for correlation of pain generators in cervical and lumbar spine is exemplified by demonstration of similar degeneration of disc in cervical and lumbar spine in twins (11).

The correlation of facet joint pain in patients with chronic neck and low back pain has not been evaluated. It was also shown that in interventional pain management settings, combined incidence of lumbar and cervical pain is significant with involvement of at least two regions in $56 \%$ of the patients and three regions in $22 \%$ of the patients (25). Thus, it is conceivable that the patients with chronic low back pain of facet joint origin, will likely also present with cervical facet joint involvement if they present with both complaints. This study was undertaken to evaluate the prevalence and correlation of facet joint pain in patients with chronic low back pain and neck pain.

\section{METHODS}

The study was designed to evaluate 120 consecutive patients presenting with complaints of chronic low back pain and neck pain, in a non-university setting, in one private comprehensive interventional pain management practice. Inclusion criteria included patients of 18 years to 90 years of age, those who exhibited no neurological deficits, those who had pain for at least 6 months, those who presented without a definite diagnosis based on findings of radiologic or neurologic testing and those who have failed conservative management. Conservative management included physical therapy, chiropractic, exercises, drug therapy, bedrest, etc., which has failed to provide significant improvement either with the neck or low back pain. Evaluation of the patients included completion of a comprehensive pain management questionnaire; history, physical examination and evaluation of the results of all procedures and investigations. All the patients consented and participated in the study after the nature of the study and the potential hazards of the procedures were explained to them.

Facet joints were investigated in all patients with diagnostic blocks using lidocaine $1 \%$, initially followed by bupivacaine $0.25 \%$ on separate occasions, usually 3 to 4 weeks apart. Injectate was prepared by mixing equal volumes of Sarapin to $2 \%$ lidocaine and $0.5 \%$ bupivacaine, with or without addition of $2 \mathrm{mg}$. of methylprednisolone to each $\mathrm{mL}$ of mixture. The blocks were performed on the ipsilateral side in patients with unilateral pain or bilaterally in patients with bilateral or axial pain. Blocks were performed at two levels at least to block a single joint. Target joints were identified by either or combination of the history of pain pattern, local paramedian or tenderness over the area overlying facet joints and reproduction of symptomatology with deep pressure. Blocks were performed under fluoroscopic visualization with a 22-gauge, 3.5-inch spinal needle under intermittent fluoroscopy at each of the medial branches at the L1-L4 and L5 dorsal ramus in the lumbar spine and with a 22-gauge, 2-inch spinal needle under intermittent fluoroscopy at each of the medial branches in the cervical spine. Each nerve was infiltrated with $0.5 \mathrm{~mL}$ of either $1 \%$ or $0.25 \%$ bupivacaine. A definite response was defined as relief of at least $80 \%$ in the symptomatic area. Following each block, the patient was examined and previously painful movements were performed. In order to be considered positive, the response to a block has to last at least 2 hours or longer when lidocaine was used; and either longer than the duration of effect from lidocaine, or at least 3 hours, when bupivacaine was used.

Intravenous access and mild sedation with midazolam were carried out in all the patients.

Data were recorded on a database using Microsoft $\AA$ Access. The SPSS version 9.0 statistical package was used to generate frequency tables. 
Table 1. Duration, onset distribution of pain and number of facet joints blocked in cervical and lumbar regions

\begin{tabular}{lcc}
\hline & Cervical & Lumbar \\
\hline $\begin{array}{l}\text { Duration of pain (months) } \\
\text { Onset of pain }\end{array}$ & $111 \pm 10.8$ & $127 \pm 11.4$ \\
$\quad$ Gradual & $58 \%$ & $51 \%$ \\
$\quad$ Following an incident & $42 \%$ & $49 \%$ \\
Distribution of pain & & \\
$\quad$ Bilateral & $70 \%$ & $60 \%$ \\
Left & $12 \%$ & $20 \%$ \\
$\quad$ Right & $18 \%$ & $20 \%$ \\
Number of joints blocked & & \\
Four & $38 \%$ & $0 \%$ \\
Three & $47 \%$ & $32 \%$ \\
Two & $15 \%$ & $68 \%$ \\
\hline
\end{tabular}

\section{RESULTS}

Total number of patients studied were 120 . Gender distribution was 30\% male vs $70 \%$ female. Mean age was $43+1.2$ years with a range of 20 to 80 years. Mean height was $66+0.3$ inches with a range of 56 to 76 inches. Mean weight was $175+4.2 \mathrm{lbs}$. with a range of 103 to 336 lbs. Table 1 illustrates salient characteristics of low back and neck pain with duration, mode of onset, and distribution. Number of joints blocked were 2 to 4 , with 3 joints blocked in $47 \%$ of patients in cervical spine, with 2 joints blocked in $68 \%$ of patients in lumbar spine. Fortyeight percent of patients were treated with bilateral facet

Table 2. Results of cervical facet joint nerve blocks (single blocks with lidocaine and double blocks with lidocaine and bupivacaine)

\begin{tabular}{lcc}
\hline & \multicolumn{2}{c}{ Double Blocks } \\
\cline { 2 - 3 } Single Block & Positive & Negative \\
\hline Positive & 80 & 25 \\
Negative & & 15 \\
Prevalence & $67 \%(95 \%$ CI $58 \%, 75 \%)$ \\
False-positive rate & $63 \%(95 \%$ CI $48 \%, 78 \%)$ \\
\hline
\end{tabular}

joint blocks in both areas, only $4 \%$ of patients with leftsided blocks in both of regions and only $5 \%$ of patients with right-sided blocks in cervical and lumbar regions.

Table 2 illustrates the results of evaluation of facet joint pain in cervical spine. One hundred and five or $88 \%$ of the patients reported a definite response to lidocaine blocks. Confirmatory blocks with bupivacaine were performed in each of these 105 patients. Of this group, 80 patients i.e., $67 \%$ of total sample or $76 \%$ of lidocainepositive group reporting definite response with improvement in their pain. This latter group provides a prevalence rate of facet joint pain for patients with chronic neck pain presenting to an interventional multidisciplinary private pain management practice of $67 \%$ (95\% CI, 58\%, $75 \%$ ). For the purposes of calculating false-positive rate, all the patients who had no response to lidocaine were assumed to be true-negative and all the patients who had a positive response to lidocaine and negative response to bupivacaine were considered to be false-positive. The resultant false-positive rate was $63 \%$ (95\% CI, 48\%, 78\%)

Table 3 illustrates the results of evaluation of facet joint pain in the lumbar spine. Sixty-nine or $58 \%$ of the patients reported a definite response to lidocaine blocks. Confirmatory blocks with bupivacaine were performed in each of these 69 patients. Of this group, 48 patients, i.e., $40 \%$ of the total sample or $70 \%$ of lidocaine-positive group 
Table 3. Results of lumbar facet joint nerve blocks (single blocks with lidocaine and double blocks with lidocaine and bupivacaine)

\begin{tabular}{lcc}
\hline \multirow{2}{*}{ Single Block } & \multicolumn{2}{c}{ Double Blocks } \\
\cline { 2 - 3 } & Positive & Negative \\
\hline Positive & 48 & 21 \\
Negative & 51 \\
Prevalence & $40 \%(95 \%$ CI $31 \%, 49 \%)$ \\
False-positive rate & $30 \%(95 \%$ CI $20 \%, 40 \%)$ \\
\hline
\end{tabular}

reporting a definite response with improvement in their pain. This latter group provides a prevalence rate of facet joint pain in patients with chronic low back pain of $40 \%$ $(95 \% \mathrm{CI}, 31 \%, 49 \%)$. The false-positive rate was $30 \%$ (95\% CI, 20\%, 40\%).

As shown in Table 4, results of cervical and lumbar facet joint blocks were correlated. Thirty-seven percent of the total patients or $94 \%$ of the patients judged to be positive for facet joint pain by the double-block algorithm were also shown to be positive for cervical facet joint pain. This provided with a prevalence rate of $37 \%$ positive for both cervical and lumbar facet joint pain in contrast to $40 \%$ with lumbar facet joint pain and $67 \%$ with cervical facet joint pain.

\section{DISCUSSION}

Among the chronic pain problems, spinal pain, which includes not only the pain emanating from lumbar and cervical spine, but also from thoracic spine, constitutes the majority of the problems (26-28). It is estimated that episodes of low back pain that are frequent or persistent have been reported in $15 \%$ of the US population, with a lifetime prevalence of $65 \%$ to $80 \%$ (28). Further, age related low back pain has been shown of significance (28).

Table 4. Correlation of results of lumbar and cervical facet joint nerve blocks

\begin{tabular}{lcc}
\hline & \multicolumn{2}{c}{ Lumbar } \\
\cline { 2 - 3 } Cervical & Positive & Negative \\
\hline Positive & 45 & 35 \\
Negative & 3 & 37 \\
\hline
\end{tabular}

While $12 \%$ of children and adolescents suffer with persistent low back pain in contrast to $15 \%$ of adults, it is reported to be as high as $27 \%$ in the elderly (28). Multiple studies also have shown an incidence of recurrent or chronic low back pain at 3 months, 6 months and 12 months to range from $35 \%$ to $79 \%$ (28). Cassidy et al (29) showed that point prevalence of low back pain as $29 \%$, 6-months prevalence of $69 \%$, and lifetime prevalence of $84 \%$ in Canada. They also showed that grades III and IV categories of back pain with disability were reported in $30 \%$ of the population.

Neck pain, though not as common as low back pain, is also encountered frequently in modern medical practices. It is considered one of the most common chronic pain conditions and a major problem in modern society behind low back pain. Côté et al $(30,31)$ in evaluating neck pain and its related disability, reported that in the Canadian population, the estimated lifetime prevalence as $67 \%$, point prevalence of $22 \%$ and $14 \%$ prevalence of high pain intensity with disability. Croft et al (32) in a longitudinal study in the general population, in the United Kingdom, with no current neck pain, reported a one-year incidence of estimated cumulative episodic neck pain of $18 \%$. Studies also have reported that $15 \%$ of whiplash patients suffer severe pain for one to three years in between $26 \%$ and $44 \%$ of the whiplash patients develop long-term problems (33).

Multiple structures in the spine, including facet joints, intervertebral discs, dorsal root ganglia, muscle and ligaments are capable of causing headaches, neck pain and shoulder pain or low back, hip and lower extremity pain. Lumbar facet joints have been shown to be capable of being a source of pain in the low back and referred pain in the lower extremity in normal volunteers (14, 34-37). Multiple authors also have shown referred pain distribution of cervical facet joints (14, 38-41). Cervical and lumbar facet joints are innervated by the medial branches of the dorsal rami (42-44).

The prevalence of lumbar facet joint pain of $40 \%$ established in this study with prevalence of false-positive rate of $30 \%$ with a single-block is similar to the most previous investigations $(15-21,45)$, whereas, $67 \%$ of cervical facet joint pain with a false-positive rate of $63 \%$ are higher than the previous reports $(22-24,46)$. A significant proportion of patients presenting to an interventional pain management setting, with chronic low back and neck pain, show evidence of facet joint pain in the low back and neck, with $94 \%$ of the patients with 
lumbar facet joint pain, also presenting with cervical facet joint pain. There is significant correlation with lumbar facet joint pain to presence of cervical facet joint pain. However, since the prevalence of cervical facet joint pain is higher than lumbar facet joint pain, even in the patients with combined chronic low back and neck pain, the decision on lumbar facet joint pain may not be based on presence of cervical facet joint pain. Thus, we consider the results of this study to be valid and reliable in interventional pain management settings in patients without evidence of radicular pain and also without response to physical therapy, chiropractic management and medical therapy.

Medial branch blocks are the only reliable diagnostic tool in chronic spinal pain, since there are no features or any form of imaging that indicate whether a facet joint is painful or not. The target specificity of medial branch blocks in the diagnosis of facet joint pain in the cervical and lumbar spine has been established (47-49). The reliability of controlled, comparative local anesthetic blocks and medial branch blocks has been addressed under stringent conditions $(14,50-52)$. The present study has evaluated clinical response appropriately with stringent criteria.

\section{CONCLUSION}

The results of this study show prevalence of lumbar facet joint pain in $40 \%$ of the patients with chronic low back pain with a false-positive rate of $30 \%$ and cervical facet joint pain in chronic neck pain in $67 \%$ of the patients with a false-positive rate of $63 \%$ with single block; in patients presenting with a combination of chronic low back and neck pain. The results of this study also show significant correlation between lumbar facet joint pain and cervical facet joint pain, with $94 \%$ of the patients with confirmed diagnosis of lumbar facet joint pain also have cervical facet joint pain when they present with both complaints.

\section{ACKNOWLEDGMENTS}

The authors wish to thank Tonie Hatton, Marla Neihoff and Lorie Caldwell for their assistance in preparation of this manuscript.

\section{REFERENCES}

1. Stein M, Elliott D, Glen J, et al. Percutaneous facet joint fusion. Preliminary experiences. Vasc Interv Radiol 1993; 4:69-74.
Maldague B, Mathurien P, Malghern J. Facet joint arthrography in lumbar spondylosis. Radiology 1981; 140:29-36.

3. Bogduk N. The zygapophysial joints. In Clinical Anatomy of the Lumbar Spine and Sacrum, Third edition. Churchill Livingstone, New York, 1997, pp 33-41.

4. Kirkaldy-Wills WH, Wedge JH, Yong-Hing K et al. Pathology and pathogenesis of lumbar spondylosis and stenosis. Spine 1978;3:319-327.

5. Fujiwara A, Tamai K, Yamato $M$ et al. The relationship between facet joint osteoarthritis and disc degeneration of the lumbar spine: An MRI study. Eur J Spine 1999; 8:396-401.

6. Fujiwara A, Tamai K, An HS. The relationship between disc degeneration, facet joint osteoarthritis, and stability of the degenerative lumbar spine. $J$ Spinal Disord 2000; 13:444-450.

7. Thompson RE, Pearcy MJ, Downing KJW. Disc lesions and the mechanics of the intervertebral joint complex. Spine 2000; 25:3026-3035.

8. Fujiwara A, Lim T, An $\mathrm{H}$ et al. The effect of disc degeneration and facet joint osteoarthritis on the segmental flexibility of the lumbar spine. Spine 2000; 25:3036-3044.

9. Handel JA, Knap J, Poletti S. The structural degenerative cascade. The cervical spine. In White AH, Schofferaian, JA (eds). Spine Care. Diagnosis and conservative treatment. Mosby, St. Louis, 1995, Vol. 1: pp 16-23.

10. Andersson GBJ. The epidemiology of spinal disorders. In White AH, Schofferaian, JA (eds). Spine Care. Diagnosis and conservative treatment. Mosby, St. Louis, 1995, Vol. 1: pp 93-141.

11. Sambrook PN, MacGregor AJ, Spector TD. Genetic influences on cervical and lumbar disc degeneration: A magnetic resonance imaging study in twins. Arthritis Rheum 1999; 42:366-372.

12. Kuslich SD, Ulstrom CL, Michael CJ. The tissue origin of low back pain and sciatica: A report of pain response to tissue stimulation during operation on the lumbar spine using local anesthesia. Orthop Clin North Am 1991; 22:181-187.

13. Goldthwait JE. The lumbosacral articulation: An explanation of many cases of lumbago, sciatica, and paraplegia. Boston Med \& Surg J 1911; 164:365-372.

14. Bogduk N. International Spinal Injection Society guidelines for the performance of spinal injection procedures. Part 1: Zygapophysial joint blocks. Clin J Pain; 1997; 13:285-302.

15. Schwarzer AC, Aprill CN, Derby R et al. Clinical features of patients with pain stemming from the lumbar zygapophysial joints. Is the lumbar facet syndrome a clinical entity? Spine 1994; 19:11321137.

16. Schwarzer AC, Wang S, Bogduk N et al. Prevalence 
and clinical features of lumbar zygapophysial joint pain: A study in an Australian population with chronic low back pain. Am Rheum Dis 1995; 54:100-106.

17. Schwarzer AC, Aprill CN, Derby R et al. The relative contributions of the disc and zygapophyseal joint in chronic low back pain. Spine 1994; 19:801-806.

18. Manchikanti L, Pampati VS, Fellows B et al. Prevalence of lumbar facet joint pain in chronic low back pain. Pain Physician 1999; 2:59-64.

19. Manchikanti L, Pampati V, Fellows B et al. The inability of the clinical picture to characterize pain from facet joints. Pain Physician 2000; 3:158-166.

20. Manchikanti L, Singh V, Pampati VS et al. Evaluation of the relative contributions of various structures in chronic low back pain. Pain Physician 2001; 4:308316.

21. Manchikanti L, Pampati VS, Fellows B et al. The diagnostic validity and therapeutic value of medial branch blocks with or without adjuvants. Curr Rev Pain 2000 4:337-344.

22. Barnsley L, Lord SM, Wallis BJ et al. The prevalence of chronic cervical zygapophyseal joint pain after whiplash. Spine 1995; 20:20-26.

23. Lord SM, Barnsley L, Wallis BJ et al. Chronic cervical zygapophysial joint pain with whiplash: A placebocontrolled prevalence study. Spine 1996; 21:17371745.

24. Manchikanti L, Singh V, Rivera J et al. Prevalence of cervical facet joint pain in chronic neck pain. Pain Physician 2002; 5:243-249.

25. Manchikanti L, Pampati V. Research designs in interventional pain management: Is randomization superior, desirable or essential? Pain Physician 2002; 5:275-284.

26. Manchikanti L, Singh V, Kloth D et al. Interventional techniques in the management of chronic pain: Part 2.0. Pain Physician 2001; 4:24-96.

27. Lawrence RC, Helmick CG, Arnett FC. Estimates of the prevalence of arthritis and selected musculoskeletal disorders in the United States. Arthritis \& Rheumatism 1998; 41:778-799.

28. Manchikanti L, Saini B, Singh V. Epidemiology of low back pain. In Manchikanti L, Slipman CW, Fellows B (eds), Interventional Pain Management: Low Back Pain: Diagnosis and Treatment. ASIPP Publishing, Paducah, KY 2002; pp 3-20.

29. Cassidy D, Carroll L, Cote P: The Saskatchewan Health and Back Pain Survey. The prevalence of low back pain and related disability in Saskatchewan Adults. Spine 1998; 23:1860-1867.

30. Côté DC, Cassidy JD, Carroll L. The Saskatchewan Health and Back Pain Survey. The prevalence of neck pain and related disability in Saskatchewan adults. Spine 1998; 23:1689-1698.
31. Côté DC, Cassidy JD, Carroll L. The factors associated with neck pain and its related disability in the Saskatchewan population. Spine 2000; 25:11091117.

32. Croft PR, Lewis M, Papageorgiou AC et al. Risk factors for neck pain: A longitudinal study in the general population. Pain 2001; 93:317-325.

33. Johnson G. Hyperextension soft tissue injuries of the cervical spine: A review. J Accid Emerg Med 1996; 13:3-8.

34. Mooney V, Robertson J. The facet syndrome. Clin Orthop 1976; 115:149-156.

35. McCall IW, Park WM, O'Brien JP. Induced pain referral from posterior elements in normal subjects. Spine 1979; 4:441-446.

36. Marks R. Distribution of pain provoked from lumbar facet joints and related structures during diagnostic spinal infiltration. Pain 1989; 39:37-40.

37. Fukui S, Ohseto K, Shiotani M et al. Distribution of referral pain from the lumbar zygapophyseal joints and dorsal rami. Clin J Pain 1997; 13:303-307.

38. Fukui S, Ohseto K, Shiotani M et al. Referred pain distribution of the cervical zygapophyseal joints and cervical dorsal rami. Pain 1996; 68:79-83.

39. Dwyer A, Aprill C, Bogduk N. Cervical zygapophyseal joint pain patterns: A study in normal volunteers. Spine 1990; 6:453-457.

40. Aprill C, Dwyer A, Bogduk N. The prevalence of cervical zygapophyseal joint pain patterns II: a clinical evaluation. Spine 1990; 6:458-461.

41. Pawl RP. Headache, cervical spondylosis, and anterior cervical fusion. Surgery Annu 1977; 9:391-498.

42. Bogduk N. The clinical anatomy of the cervical dorsal rami. Spine 1982; 7:319-330.

43. Suseki K, Takahashi Y, Takahashi K, et al. Innervation of the lumbar facet joints. Spine 1997; 22:477-485.

44. Bogduk N, Wilson AS, Tynan W. The human lumbar dorsal rami. J Anat 1982; 134:383-397.

45. Schwarzer AC, Aprill CN, Derby R et al. The falsepositive rate of uncontrolled diagnostic blocks of the lumbar zygapophysial joints. Pain 1994; 58:195-200.

46. Barnsley L, Lord S, Wallis B et al. False-positive rates of cervical zygapophysial joint blocks. Clin $J$ Pain 1993; 9:124-130.

47. Barnsley L, Bogduk N. Medial branch blocks are specific for the diagnosis of cervical zygapophyseal joint pain. Reg Anesth 1993; 18:343-350.

48. Dreyfuss P, Schwarzer AC, Lau P et al. Specificity of lumbar medial branch and L5 dorsal ramus blocks: A computed tomography study. Spine 1997; 22:895-902.

49. Kaplan M, Dreyfus P, Halbrook B et al. The ability of lumbar medial branch blocks to anesthetize zygapophysial joint. Spine 1998; 23:1847-1852. 
50. Bogduk N, Lord S. Cervical zygapophysial joint pain.

52. Neurosurgery 1998; 8:107-117.

51. Barnsley L, Lord S, Bogduk N. Comparative local anesthetic blocks in the diagnosis of cervical zygapophysial joints pain. Pain 1993; 55: 99-106.
Lord SM, Barnsley L, Bogduk N. The utility of comparative local anesthetic blocks versus placebocontrolled blocks for the diagnosis of cervical zygapophysial joint pain. Clin J Pain 1995; 11:208213. 